\title{
Oxidative Stress in Iron Deficiency Anaemia - A Gender-Based Analysis - A Pilot Study
}

\author{
Raghava Sharma ${ }^{1}$, Hrishikesh Nachane ${ }^{2}$ \\ ${ }^{1}$ Department of Medicine, KS Hegde Medical Academy, Deralakatte, Mangalore, Karnataka, India. \\ ${ }^{2}$ Department of Psychiatry, TNMC\&BYL Nair Hospital, Mumbai, India.
}

\section{ABSTRACT}

\section{BACKGROUND}

Nutritional anaemia especially iron deficiency anaemia is one of the important medical problems in tropical areas and India. Role of oxidative stress in the pathogenesis of Iron Deficiency Anaemia (IDA) has been established. Oxidative stress is one of the accompaniments in the pathology of IDA which also leads to defective production of other iron containing proteins especially cytochrome, peroxidase, catalase etc. However, different studies have assessed different variables. Especially cut-offs for diagnosis, qualitative properties of erythrocytes, prevalence and complication rates in IDA. Research into gender differences in oxidative stress in IDA is particularly lacking.

\section{METHODS}

The present study aimed to elucidate oxidative stress in IDA by measuring the levels of malondialdehyde (MDA), superoxide dismutase (SOD) and total antioxidant capacity (TAC). We compared these levels among men and women with anaemia and without anaemia (i.e., healthy controls). 36 IDA patients (18 men and 18 women) and 48 healthy controls were recruited. $5 \mathrm{~mL}$ blood was drawn and assessed for MDA, SOD and TAC levels. One-way ANOVA with post-test Bonferroni was used for statistical analysis.

\section{RESULTS}

Anaemic women had significantly lower iron than anaemic men $(\mathrm{p}<0.01)$. MDA levels were significantly higher in subjects with IDA $(\mathrm{p}<0.01)$, with levels being higher in women. SOD levels were higher in anaemic men as compared to anaemic women $(p<0.01)$. TAC levels did not vary significantly $(p=0.09)$.

\section{CONCLUSIONS}

Oxidative stress is present in IDA, which is more severe and less compensated in women as compared to men.

\section{KEY WORDS}

Iron Deficiency Anaemia, Oxidative Stress, Gender Differences, MDA, SOD, TAC
Corresponding Author: Dr. Raghava Sharma, Department of Medicine, KS Hegde Medical Academy, Deralakatte, Mangalore-575018, Karnataka, India.

E-mail:rrsharma1967@yahoo.com

DOI: $10.14260 /$ jemds/2020/821

How to Cite This Article:

Sharma R, Nachane H. Oxidative stress in iron deficiency anaemia- a gender-based analysis - a pilot study. J Evolution Med Dent Sci 2020;9(49):3739-3742, DOI: 10.14260/jemds/2020/821

Submission 11-08-2020,

Peer Review 07-10-2020,

Acceptance 14-10-2020,

Published 07-12-2020.

Copyright (C) 2020 Raghava Sharma et al. This is an open access article distributed under Creative Commons Attribution License [Attribution 4.0 International (CC $B Y 4.0)]$ 


\section{BACKGROUND}

Iron Deficiency Anaemia (IDA) is the most common type of anaemia in clinical practice. ${ }^{1}$ The central pathology in IDA appears to be decreased haemoglobin production leading to reduced oxygen carrying capacity in the body. ${ }^{2}$ Iron deficiency also affects production of other proteins containing iron, such as cytochromes, myoglobin, catalase, and peroxidase. ${ }^{3}$ This paved way for the role of oxidative stress in the pathology of IDA. Normally, there exists a balance between production of free radicals and reactive oxygen species and antioxidant defence mechanisms both enzymatic and non-enzymatic. ${ }^{4}$ If this is disturbed, it leads to the production of oxidative stress. Recent literature has illustrated that the oxidative/antioxidative balance shifts towards the oxidative side in IDA. ${ }^{5}$ Gender differences in various aspects of anaemia have been established. ${ }^{6}$ Having different cut offs for diagnosis, different qualitative properties of erythrocytes and blood, difference in prevalence and complication rates include some of them. ${ }^{6}$ No study has looked into gender differences in oxidative stress in IDA. Understanding gender difference in IDA from the purview of oxidative stress assumes importance as this can shed light upon occurrence of clinical gender-based variance in IDA.

Earlier research has evaluated IDA by assessing a variety of biochemical variables. ${ }^{5}$ The present study focused on three parameters of oxidative stress: Malon-Di-Aldehyde (MDA), Super-Oxide Dismutase (SOD) and Total Antioxidant Capacity (TAC). MDA, a reactive aldehyde, formed due to degradation of polyunsaturated lipids by reactive oxygen species is one of the many reactive electrophile species that cause toxic stress in cells. ${ }^{7}$ SOD constitute a class of enzymes primarily responsible for the catalysation of the dismutation of superoxide in to oxygen and hydrogen peroxide, forming an important antioxidant defence in nearly all oxygen exposed cells. ${ }^{8}$ TAC is the measure of the amount of free radicals scavenged by any given sample and is used to evaluate the antioxidant capacity of biological samples. ${ }^{9}$ It carries the advantage of being a global assessment of a biological sample's antioxidant capacity in a cheap and less timeconsuming manner. ${ }^{9}$ Analysing oxidants and antioxidants together is encouraged as it gives a better picture of the oxidative status. Studies undertaking comparison among men and women in IDA with respect to these markers are lacking. Hence, the present analysis aimed to assess the levels of MDA, SOD and TAC in IDA and present a gender-based analysis of the same.

\section{METHODS}

The present cross-sectional observational study (pilot study) was conducted at the medical college hospital for a period of six months with effect from October 2011 in coastal Karnataka, India. The study was in accordance with Declaration of Helsinki and ethical clearance was obtained from the Institutional Ethical Committee. 36 subjects. Those who could be accommodated for free laboratory services pertaining to estimation of oxidative stress on a pilot basis diagnosed with IDA and who were drug naïve were recruited from the medicine outpatient department. They consisted of 18 men and 18 women. IDA was diagnosed as haemoglobin levels less than $12 \mathrm{~g} / \mathrm{dL}$ for women and $13 \mathrm{~g} / \mathrm{dL}$ for men, with peripheral blood smear confirming the diagnosis as per WHO 1994 (as fully described under Indicators and strategies for iron deficiency and anaemia programmes: Report of the WHO/UNICEF/UNU consultation, Geneva, Switzerland, 6-10 December 1993). 48 healthy controls (age, sex matched) were selected from the normal population. A brief medical history was obtained from all participants and subjects with other comorbid condition which could affect oxidative stress, such as diabetes, renal disease, malignancies, etc. were excluded. A written informed consent was taken from all participants. Participants were categorized into four categories: 1. Consisting of anaemic women, 2. Consisting of anaemic men, 3 . Consisting of healthy women controls and 4 . Consisting of healthy men controls. A sample of venous blood (5 $\mathrm{mL}$ ) was taken from the subjects under aseptic precautions. This was then assessed for MDA, SOD and TAC. The study was performed during the short period when laboratory resources were available for the estimation of MDA, SOD, and TAC without any financial liabilities for all the four categories. The following procedures were followed:

\section{Estimation of MDA}

MDA was assessed by modified Trichloroacetic AcidThiobarbituric Acid (TCA - TBA) method. ${ }^{10} 0.5 \mathrm{~mL}$ of serum sample was added to $3 \mathrm{~mL}$ of $10 \%$ TCA, mixed well and left to stand for 10 minutes. It was then centrifugation for 15 minutes at $5000 \mathrm{rpm} .2 \mathrm{~mL}$ of supernatant fluid from this mixture was then taken to which $1.5 \mathrm{~mL}$ of $0.67 \%$ TBA was added. A pale pink colour develops, whose intensity was measured at $530 \mathrm{~nm}$.

\section{Estimation of SOD}

SOD was measured by the Nitro Blue Tetrazolium (NBT) technique. ${ }^{11} 2.5 \mathrm{~mL}$ of methionine phosphate buffer, $1 \mathrm{x} 10^{-2}$ M methionine, $16.8 \times 10^{-5} \mathrm{M}$ NBT and $1.17 \times 10^{-6} \mathrm{M}$ riboflavin with suitably diluted erythrocyte haemolysates was mixed in a total volume of $3 \mathrm{~mL}$. The illumination of the solution was carried out in an aluminium foil lined box, with a $15 \mathrm{~W}$ fluorescent lamp, for 10 minutes. The absorbance was measured at $560 \mathrm{~nm}$.

\section{Estimation of TAC}

The total antioxidant capacity was analysed by the phospho molybdenum technique. ${ }^{2}$ The serum was treated with $5 \%$ trichloroacetic acid and the deproteinised sample was then subsequently treated with the TAC reagent $(28 \mathrm{mM}$ sodium dihydrogen phosphate and $4 \mathrm{mM}$ ammonium heptamolybdate, in $0.6 \mathrm{M}$ of concentrated sulphuric acid) at $90{ }^{\circ} \mathrm{C}$ for 90 minutes in a water bath. Following incubation, the mixture was cooled, and the optical density of the green complex formed was read at $695 \mathrm{~nm}$.

\section{Statistical Analysis}

Results are expressed as mean \pm standard deviation. SPSS 20.0 was used for statistical analysis. Significance across 
groups was determined by one-way ANOVA with post hoc test Bonferroni for difference within individual groups. $\mathrm{P}$ values $<0.05$ were considered significant.

\section{RESULTS}

Table 1 illustrates our findings. Levels of iron were significantly lower in anaemic women as compared to anaemic men, but higher in normal women as compared to normal men $(p<0.01)$. Analysing the oxidative markers showed that levels of MDA were significantly different across the four categories $(p<0.01)$. Post-test Bonferroni's analysis revealed that significant difference was seen between anaemic women and healthy women at $\mathrm{p}<0.05$ level; and anaemic men and normal men at $\mathrm{p}<0.01$ level; with levels being higher in the anaemic groups. Levels of SOD also showed significant difference across the four categories $(\mathrm{p}<$ 0.01), with post hoc test Bonferroni's analysis showing significant difference between anaemic men and women at $p$ $<0.01$ level; and the levels being higher in men. Levels of TAC did not vary significantly across the categories $(p=0.09)$.

\begin{tabular}{|c|c|c|c|c|c|c|}
\hline $\begin{array}{l}\text { Sl. } \\
\text { No. }\end{array}$ & Variable & $\begin{array}{c}\text { Category } 1 \\
\text { (Anaemic } \\
\text { Women) } \\
\mathbf{n}=18\end{array}$ & $\begin{array}{c}\text { Category } 2 \\
\text { (Anaemic } \\
\text { Men) } \\
\mathbf{n}=18\end{array}$ & $\begin{array}{c}\text { Category } 3 \\
\text { (Healthy } \\
\text { Women) } \\
\mathbf{n}=\mathbf{2 4}\end{array}$ & $\begin{array}{c}\text { Category } 4 \\
\text { (Healthy Men) } \\
\mathbf{n}=\mathbf{2 4}\end{array}$ & Value \\
\hline 1 & $\begin{array}{l}\text { Serum Iron }(\mu \mathrm{g} / \\
\mathrm{dL})\end{array}$ & $141.56 \pm 33.09$ & $156.11 \pm 31.58$ & $181.69 \pm 37.96$ & $178.00 \pm 46.50$ & $\begin{array}{c}< \\
0.01^{*}\end{array}$ \\
\hline 2 & $\begin{array}{l}\text { Malondialdehyde } \\
\text { (MDA; } \mu \mathrm{M} / \mathrm{L})\end{array}$ & $3.70 \pm 0.51^{\dagger}$ & $3.13 \pm 0.75^{\ddagger}$ & 2.79 & 2.40 & $\begin{array}{c}< \\
0.01^{*}\end{array}$ \\
\hline 3 & $\begin{array}{l}\text { Superoxide } \\
\text { Dismutase } \\
\text { (SOD; } \mathrm{U} / \mathrm{g} \mathrm{Hb})\end{array}$ & $\begin{array}{c}1124.98 \pm \\
140.63 \ddagger\end{array}$ & $\begin{array}{c}1342.86 \pm 85.67 \\
\ddagger\end{array}$ & $\begin{array}{c}1138.66 \pm \\
193.48\end{array}$ & $\begin{array}{l}1283.06 \\
\pm 193.19\end{array}$ & $\begin{array}{c}< \\
0.01^{*}\end{array}$ \\
\hline 4 & $\begin{array}{l}\text { Total Antioxidant } \\
\text { Capacity } \\
\text { (TAC; } \mu \mathrm{g} / \mathrm{mL})\end{array}$ & $120.52 \pm 13.17$ & $133.95 \pm 16.97$ & $110.19 \pm 30.34$ & 128.8 & 0.09 \\
\hline \multicolumn{7}{|c|}{$\begin{array}{l}\text { Table 1. Comparison of Serum Iron, Malondialdehyde, Superoxide } \\
\text { Dismutase and Total Antioxidant Capacity among the Four Groups }\end{array}$} \\
\hline \multicolumn{7}{|c|}{$\begin{array}{l}\text { *Indicates statistically significant } \\
\dagger \text { Significant at } \mathrm{p}<0.05 \text { level in the Post Test Analysis. } \\
\neq \text { Significant at } \mathrm{p}<0.01 \text { level in the Post Test Analysis. } \\
\text { Data Expressed as Mean } \pm \text { Standard Deviation. }\end{array}$} \\
\hline
\end{tabular}

\section{DISCUSSION}

Studies done on oxidative stress in IDA have hitherto analysed oxidants, antioxidants or both. ${ }^{13}$ The present analysis is an attempt to further this knowledge by analysing gender variations in oxidative status. Iron levels in anaemic women were significantly lower than anaemic men. Women especially in the childbearing age group tend to have lower haemoglobin, ferritin and iron levels than men and women of other age groups ${ }^{14}$ and this was seen in our trends. Subjects with IDA were shown to have more oxidative stress as compared to healthy controls, which was established by an increase in MDA levels. Similarly, other researchers have established decreased antioxidant defence in iron deficiency mainly due to a significant increase in lipid peroxidation, resulting in elevated MDA levels. ${ }^{5}$ Levels of MDA have also been shown to normalize post treatment, indicating oxidative stress is closely linked to haemoglobin and iron levels.
Looking into SOD levels, the present study showed elevated SOD levels in anaemic subjects. Increased SOD activity in IDA has been attributed to a compensatory reaction to the oxidative stress and other researchers have replicated this finding. ${ }^{15}$ Other research showed decreased activities of antioxidant enzymes, such as SOD, glutathione and catalase in patients with IDA. ${ }^{16}$ It appears that erythrocytes in IDA are more susceptible to oxidation but had good capacity for recovery, which could lead to elevated SOD levels. ${ }^{16}$ In such cases, elevated SOD levels can be considered as a compensatory mechanism to existing oxidative stress. The fact that anaemic women having higher MDA and lower SOD as compared to anaemic men as proved in the present study implies that anaemic women have a weaker compensatory mechanism as compared to anaemic men. This makes them prone to develop more severe symptoms and complications of IDA in comparison to their male counterparts. Gender differences in quality of erythrocytes have been established and perhaps this also translates into their antioxidizing abilities. ${ }^{7}$ In our analysis, TAC levels did not vary significantly among the categories. However, other studies have shown a significant reduction in TAC in IDA. ${ }^{17}$

\section{CONCLUSIONS}

Oxidative stress exists in IDA, which can manifest in elevation of both oxidants and antioxidants (as a compensatory mechanism). The present study shows that levels of both would be ideal in arriving at a reasonable conclusion of oxidative status. Severity of oxidative stress and compensatory ability seem to be worse in anaemic women than men. MDA and SOD appear to be more sensitive markers of oxidative stress than TAC, especially when gender differences are concerned. This study cements the role of oxidative stress in pathogenesis of IDA.

\section{Limitations of Study}

Small unequal sample size: This is mainly due to availability of specialized laboratory resources without any financial implications to all the four categories studied. Large studies in this area including more number of IDA cases and healthy controls are needed.

Data sharing statement provided by the authors is available with the full text of this article at jemds.com.

Financial or other competing interests: None.

Disclosure forms provided by the authors are available with the full text of this article at jemds.com.

\section{REFERENCES}

[1] DeLoughery TG. Iron deficiency anaemia. Med ClinNorth Am 2017;101(2):319-32.

[2] Isler M, Delibas N, Guclu M, et al. Superoxide dismutase and glutathione peroxidase in erythrocytes of patients with iron deficiency anaemia: effects of different treatment modalities. Croat Med J 2002;43(1):16-9. 
[3] Rockey DC, Cello JP. Evaluation of the gastrointestinal tract in patients with iron-deficiency anaemia. NEngl J Med 1993;329(23):1691-5.

[4] Halliwell B. Free radicals, antioxidants and human disease: curiosity, cause or consequence? Lancet 1994;344(8924):721-4.

[5] YooJH, MaengHY, Sun YK, et al. Oxidative status in iron-deficiency anaemia.J Clin Lab Anal 2009;23(5):31923.

[6] Kameneva MV, WatachMJ, Borovetz HS. Gender difference in rheologic properties of blood and risk of cardiovascular diseases. Clin HemorheolMicrocirc 1999;21(3-4):357-63.

[7] Rio DD, Stewart AJ, Pellegrini N. A review of recent studies on malondialdehyde as toxic molecule and biological marker of oxidative stress.NutrMetabCardiovasDis 2005;15(4):316-28.

[8] Nagami H, Yoshimoto N, Umakoshi H, et al. Liposomeassisted activity of superoxide dismutase under oxidative stress.J BiosciBioeng 2005;99(4):423-8.

[9] Erel 0. A novel automated direct measurement method for total antioxidant capacity using a new generation, more stable ABTS radical cation. ClinBiochem 2004;37(4):277-85.

[10] BeuegeJA, Aust SD. Microsomal lipid peroxidation. Methods Enzymol1978;52:302-10.
[11] Sun YI, OberleyLW, Li Y. A simple method for clinical assay of superoxide dismutase. Clin Chem 1988;34(3):497-500.

[12] Hegde MN, Hegde ND, Ashok A, et al. Evaluation of total antioxidant capacity of saliva and serum in caries-free and caries-active adults: an in-vivo study. Indian J Dent Res 2013;24(2):164-7.

[13] Tekin D, Yavuzer S, Tekin M, et al. Possible effects of antioxidant status on increased platelet aggregation in childhood iron-deficiency anaemia. Pediatr Int 2001;43(1):74-7.

[14] Levi M, Simonetti M, Marconi E, et al. Gender differences in determinants of iron-deficiency anaemia: a population-based study conducted in four European countries.AnnHematol 2019;98(7):1573-82.

[15] Acharya J, Punchard NA, Taylor JA, et al. Red cell lipid peroxidation and antioxidant enzymes in iron deficiency. Eur JHaematol 1991;47(4):287-91.

[16] Bartal M, Mazor D, Dvilansky A, et al. Iron deficiency anaemia: recovery from in vitro oxidative stress. Acta Haematol 1993;90(2):94-8.

[17] Aslan M, Horoz M, Çelik H. Evaluation of oxidative status in iron deficiency anaemia through total antioxidant capacity measured using an automated method. Turk JHematol2011;28(1):42-6. 